\title{
A filosofia da medicina de Edmund Pellegrino e os dilemas bioéticos relacionados ao suicídio assistido
}

Daiane Martins Rocha ${ }^{1}$

\section{Resumo}

Apesar da crescente ênfase dada à autonomia no processo de tomada de decisões, a mera decisão autônoma nem sempre reflete o bem do paciente. Este artigo sustentará, a partir da filosofia da medicina de Edmund Pellegrino, que o bem do paciente é composto por quatro elementos, um delimitando o outro, com vistas a assegurar maior equilíbrio entre o bem como avaliado pelo médico e o bem como compreendido pelo paciente. A abordagem teleológica da medicina, ou seja, uma abordagem baseada no telos (fim) da medicina, delineia até que ponto as decisões do paciente são condizentes com o seu bem. Segue-se que os pedidos de pacientes por procedimentos como o suicídio assistido não estão acordes com esse fim, e que caberia aos profissionais de saúde fornecer alternativas para prevenir e aliviar o sofrimento dos pacientes, no que se insere a temática dos cuidados paliativos.

Palavras-chave: Ética. Temas bioéticos. Bioética. Suicídio assistido. Cuidado paliativo.

\section{Resumen}

La filosofía de Edmund Pellegrino de la medicina y los dilemas bioéticos relacionados con el suicidio asistido

Pese al creciente énfasis en la autonomía en el proceso de toma de decisiones, la mera decisión autónoma no siempre refleja el bien del paciente. Se mantendrá en este artículo desde la Filosofía de la Medicina de Edmund Pellegrino que el bien del paciente se compone de cuatro elementos, un elemento delimita el otro, con el fin de garantizar mayor equilibrio entre el bien evaluado por el médico y el bien comprendido por el paciente. El enfoque teleológico de la medicina, es decir, un enfoque basado en el telos (final) de la medicina, define la medida en que las decisiones son consistentes con el bien del propio paciente. Se entiende que las solicitudes de los pacientes para procedimientos como el suicidio asistido no están de acuerdo con este fin, y que correspondería a los profesionales de la salud ofrecen alternativas para prevenir y aliviar el sufrimiento de los pacientes, donde se introduce el tema de los cuidados paliativos.

Palabras-clave: Ética. Discusiones bioéticas. Bioética. Suicidio asistido. Atención paliativa.

\section{Abstract}

The Philosophy of Medicine of Edmund Pellegrino and the bioethical dilemmas related to assisted suicide

Despite the growing emphasis given to autonomy on the decision-making process, mere autonomous decision does not always reflect the patient's welfare. In this article it is sustained from Edmund Pellegrino's Philosophy of Medicine, that the patient's welfare is composed of four elements, one delimiting the other, to ensure a balance between welfare as assessed by the doctor and the welfare as understood by the patient. The teleological approach to medicine, i.e., an approach based on telos (end) of medicine, defines the degree to which the patient's decisions are consistent with his or her own welfare. It follows that the patient's requests for procedures such as physician-assisted suicide are not in accordance with this end, so, it would be the role of health professionals to make their best to provide alternatives to prevent and relieve the suffering of patients, and in this point it's inserted the topic of palliative care.

Key words: Ethics. Bioethical issues. Bioethics. Assisted suicide. Palliative care.

1. Doutoranda daiane.mar@gmail.com - Universidade Federal de Santa Catarina, Florianópolis/SC, Brasil.

Correspondência

Rua Afonso Luiz Borba, 440, Lagoa da Conceição CEP 88062-040. Florianópolis/SC, Brasil.

Declara não haver conflito de interesse. 
Com base em quê podemos falar de beneficência nas práticas médicas? Como podemos defender valores universais em uma sociedade pluralista? Pellegrino, médico e professor do Kennedy Institute of Ethics (Georgetown University), sugere que, no caso das práticas médicas, o que rege a relação médico-paciente é o fim da medicina, a saber, oferecer a cura, ou quando essa não é possível, todo o cuidado paliativo possível, sempre visando aos melhores interesses do paciente. A filosofia da medicina, conforme estruturada por Pellegrino e Thomasma em For the patient's good ${ }^{1}$, tem como base o telos ou fim da medicina - e de acordo com esse enfoque poderíamos compreender quais práticas/ações seriam moralmente corretas para alcançar tal propósito.

Utilizando esta abordagem, o presente artigo intenta mostrar que, apesar da crescente ênfase na autonomia no processo de tomada de decisões decorrente das sociedades liberais, a mera decisão autônoma nem sempre reflete o bem do paciente, pois a autonomia é apenas um dos elementos que o compõem. Apresentaremos, então, o bem do paciente como sendo composto por quatro elementos, nos quais um delimita o outro, com vistas a assegurar maior equilíbrio no que se refere ao bem conforme concebido pelo médico e o bem como entendido pelo paciente, pois, a nosso ver, nem um nem outro pode, sozinho, definir a complexidade do bem do paciente.

A abordagem teleológica da ética biomédica a ser apresentada fornece respostas suficientes e coerentes para muitos dos dilemas bioéticos, pois envolve a elucidação do que seja o fim da medicina, a busca dos melhores interesses do paciente, além de esclarecer o conceito de futilidade e a afirmação da importância da confiança na relação médico-paciente - pois apenas por meio dessa confiança o médico pode realizar o fim (telos) a que sua atividade se destina. Cabe ressaltar que por confiança Pellegrino se refere não a um poder do médico sobre o paciente, o que se configuraria em paternalismo, mas na confiança que o paciente tem de que o médico agirá de acordo com os seus melhores interesses, tendo conhecimento e habilidades para tal.

Nossa discussão é acerca da aceitação dos fundamentos oferecidos para essa filosofia da medicina, ou seja, por que deveríamos aceitar como base da bioética uma abordagem teleológica da medicina ao invés da construção social dessas práticas? Por que deveríamos admitir um essencialismo em medicina ao invés de aceitar que cada povo e cultura podem ter diferentes expectativas em torno do profissional de saúde (como no caso de pacientes que desejam fazer um aborto, ou receber suicídio medicamente assistido)?

\section{Bioética e a questão da fundamentação}

A bioética, com origem em um discurso interdisciplinar, tem enfrentado várias dificuldades concernentes à perda de seu caráter normativo e fundamentação. $O$ que tem prevalecido são as ideias de construção social, ética discursiva e diálogo, que dão ênfase a esse caráter interdisciplinar, mas deixam de lado o aspecto da fundamentação ética e sua normatividade. Epistemologicamente, bioética significa o estudo sistemático das questões morais no que se refere à aplicação do conhecimento biológico para relações humanas tais como agricultura e ecologia, medicina e políticas públicas. Por essa definição entende-se que a bioética implicaria na busca de uma verdade moral e certa normatividade que disso se segue.

Com o lluminismo (Aufklärung) reforçou-se a ideia de uma ética livre de base religiosa e de qualquer metafísica, baseando a verdade moral na razão humana. Porém, hoje os pós-modernistas questionam mesmo a nossa capacidade de chegar a um conhecimento moral pela razão, ou seja, há uma descrença de que se possa acessar uma verdade moral por meio da razão, o que torna a negociação o único recurso para um conflito ético, haja vista que a própria racionalidade perdeu sua credibilidade.

Como salienta Pellegrino, no artigo "Bioethics at the century's turn", a ética hoje aplicada é vista em termos de conciliação de valores ou a encontrar o que possa ser uma decisão confortável. Mas sentimentos e valores não são normas e não carregam o peso moral de uma norma. Refletem crenças subjetivas e sobre eles não se pode argumentar. Paralelamente, as normas têm certo grau de objetividade e são fundamentadas em alguma concepção de verdade, do que é bom, correto ou errado. Mas não são autojustificáveis, ou seja, podemos argumentar acerca das normas. Assim, para o autor, reduzir o conflito moral a um conflito de valores é fazer da ética uma troca de opiniões ${ }^{2}$.

Como resultado da pluralidade de valores, a única norma aceitável seria a de respeitar os valores das outras pessoas, simplesmente por serem seus valores. No caso de conflitos entre valores, o impasse pode ser resolvido, na melhor das hipóteses, mediante uma decisão; e na pior, por meio de confrontação violenta. Por isso, não se pode abrir mão da base normativa da bioética, pois as decisões clíni- 
cas não podem se basear apenas nos valores e crenças das pessoas, quer médicos ou pacientes, haja vista que toda crença está sujeita a avaliação moral. As sociedades e o conhecimento biológico vão continuar se expandindo e as decisões no campo bioético não podem ficar à mercê de conflitos de valores e parâmetros tais como construção social, equilíbrio reflexivo ou diálogo.

O abandono de normas em favor de concepções do que funciona ou é útil se configura na erosão do componente ético da bioética e acarreta riscos tanto no nível individual quanto no público e internacional. Hoje, um dos desafios para a bioética é resgatar e preservar a credibilidade ética e seu conteúdo normativo, com aplicação e aceitação universal, de modo a conviver com seu caráter multidisciplinar sem ser absorvida por essas disciplinas.

A bioética surgiu ao mesmo tempo em dois diferentes ambientes e distintas abordagens. Na Georgetown University, como abordagem da ética normativa aplicada à prática médica. Na University of Wisconsin, como uma busca científica de forma mais ampla e interdisciplinar, com raízes na biologia, estendendo-se de ecologia e populações à biologia molecular. Em muitas universidades o ensino de bioética contempla elementos das duas abordagens, reforçando seu caráter interdisciplinar, embora isso possa causar a perda de sua identidade à medida que a bioética perde seu caráter normativo - como salienta Pellegrino.

A bioética, quando pautada em valores ao invés de normas, passa a ser um empreendimento subjetivo e sobre o qual não se pode argumentar. Assim, a bioética hoje necessita retomar e reforçar seu caráter normativo, em prol de certa universalidade, pois, mesmo considerando as diferenças culturais entre diferentes povos, crenças e religiões, a ética nas relações médico-paciente está sujeita a algum grau de objetividade, sem o qual a profissão se esvazia de seu sentido e telos.

O perigo da substituição de normas, princípios e preceitos por valores é que estes são subjetivos, o que faz com que a bioética perca a sua identidade no tocante à normatividade da ética. Assim, o que o autor salienta é que, embora as humanidades, as ciências sociais e físicas contribuam para compreender a dimensão moral da vida humana e sejam a substância para a ética descritiva, os fatos, observações, histórias e percepções não são normas. E sem normas de ação a ética não existe. A ética envolve reflexão sobre o que deve ser feito, de modo a analisar se a conduta humana é boa ou má, certa ou errada.
Embora muito se tenha enfatizado o papel das práticas, aquelas sem profunda fundamentação perdem credibilidade entre noções distintas de certo e errado. Como resultado, o discurso ético é reduzido ao consenso quanto às informações, confundindo uma virtude da prática política com uma fundamentação para a escolha moral. Quando se fala de fundamentação em ética, fala-se de princípios que funcionam como guias de ação, a partir dos quais se dirá se uma ação pode ser considerada boa ou má. Se deixarmos de lado a fundamentação ética, a bioética passa a servir aos interesses de diferentes grupos que oferecem as instalações, serviços e medicamentos, ou mesmo aos interesses de governantes ou grupos que detêm o poder. $\mathrm{O}$ bem do paciente fica como aspecto secundário.

\section{Abordagem teleológica da bioética versus construção social}

O fim da medicina, ou telos, como ressalta Pellegrino, não pode ser fruto de mera construção social, servindo aos interesses econômicos, sociais, estatais ou de instituições e pesquisadores envolvidos no tratamento do paciente. Por isso, o autor ressalta a importância de considerar os aspectos culturais da relação médico-paciente, não enquanto base dessa relação, mas sim relacionado ao respeito às escoIhas autônomas do paciente acerca do tratamento ou de sua descontinuidade.

Quando consideramos o modelo apresentado por Pellegrino - beneficência-na-confiança-, percebemos que engloba tanto aspectos clínicos quanto pessoais, já que o bem do paciente só pode ser alcançado quando de acordo com seus melhores interesses (o que envolve suas escolhas pessoais, cultura, religião etc.). Por conseguinte, basear as práticas médicas em uma ideia de telos ao invés de construção social é uma forma de proteger os pacientes de interesses de outros que possam gerar ações que não necessariamente estariam visando os seus meIhores interesses.

Além disso, uma abordagem da bioética com base no telos da medicina garante que a ética não seja apenas parte do nome bioética, mas também das práticas, impedindo que abordagens econômicas e relações de contrato minem as bases da relação médico-paciente - que deve ser de confiança. Ao dar ênfase nos contratos e aspectos econômicos, essas abordagens esvaziam o caráter filosófico e crítico da bioética, restando apenas regras e procedimentos que sejam convenientes às empresas de 
planos de saúde, instituições hospitalares, indústrias farmacêuticas e arrecadação de órgãos para transplante.

Assim, basear as práticas médicas em algo que não o telos da medicina gera o risco de que vários interesses sejam visados, deixando o paciente em situação ainda mais vulnerável do que a decorrente da própria doença. Mas então, se aceitamos a ideia de que as práticas médicas deveriam ser reguladas pelo telos da medicina, cabe indagar que telos é esse? Qual é o fim da medicina? Ou indo além, o que é medicina?

\section{Discussão sobre o telos e os princípios éticos}

Para Pellegrino, rever os conceitos básicos em medicina é imprescindível, especialmente considerando as grandes mudanças ocorridas na área nos últimos anos, sobretudo a partir do avanço biotecnológico, que fazem com que reavaliemos os conceitos de saúde e doença. Como salienta o autor, conceitos são a moeda do discurso filosófico ${ }^{3}$, e quando os conceitos são modificados seriamente somos sujeitos à desorientação intelectual e moral. E quando conceitos como os de saúde e doença não estão claros, o próprio conceito de medicina se torna opaco, já que, definindo-se o que é medicina, todos os demais conceitos básicos são moldados, como o de futilidade, fim da medicina, bem do paciente e autonomia.

A enorme expansão do conhecimento científico aumentou as expectativas a respeito do poder da medicina de melhorar a qualidade e duração da vida humana e, até mesmo, criar a ilusão da imortalidade mediante o progresso tecnológico. Com esse progresso, o conceito de doença passa a ser questionado, pois mesmo as mais simples limitações humanas não são mais toleradas, haja vista que podem ser sujeitas a tratamento clínico. Por exemplo, estar acima do peso, ter baixa expectativa de vida, ter QI (Quociente de Inteligência) abaixo da média ou ser de baixa estatura pode ser considerado doença? Da mesma forma poderíamos pensar acerca da menopausa, adolescência, hiperatividade em crianças e infertilidade. Poderiam todas essas condições ser consideradas doenças, definidas a partir da disponibilidade de tratamento?

Para Pellegrino, ao responder a pergunta 'o que é medicina?' respondemos a todas essas questões, bem como podemos ver com clareza que práticas são moralmente corretas e quais não deveriam ser toleradas. Com a definição desses conceitos po- demos, certamente, ter um panorama geral do que a bioética clínica é hoje, seus principais problemas e, mesmo, propostas de soluções.

Conforme ressalta o autor, a beneficência é o primeiro princípio em ética médica, já que o telos dessa profissão é o paciente e seus interesses. Por isso, ao se falar da racionalização de recursos estamos nos referindo à restrição do fornecimento de tratamentos fúteis, desnecessários, e não da limitação de recursos a tratamentos necessários, pois isso seria moralmente problemático. Do mesmo modo, destaca que fazer tudo o que for possível não é sinônimo de uma boa prática médica. Afinal, deve-se fazer tudo o que for medicamente recomendável e de acordo com os interesses do paciente, considerando o conceito de futilidade médica conforme os critérios defendidos pelo autor: eficácia, benefício e encargos de um tratamento.

A concepção de medicina defendida por Pellegrino, de que os profissionais de saúde devem agir de acordo com os melhores interesses do paciente, implica, sobretudo, em agir não apenas de acordo com o bem médico, mas também com a percepção que o paciente tem de seu próprio bem, suas preferências, valores, metas e aspirações. Isso significa que, ainda que as práticas médicas não devam ser guiadas meramente pelas preferências do paciente, quando tais preferências não forem nocivas a ele próprio devem ser atendidas, pois integram sua própria concepção de bem e, por conseguinte, de sua autonomia.

Para que a relação médico-paciente ocorra de forma apropriada faz-se preciso confiança. Por confiança o autor não entende confiança na infalibilidade do médico, mas a crença na profissão do médico e ao que ele se propõe, que seria agir de acordo com os melhores interesses do paciente. Ou seja, nessa relação os interesses econômicos ou pessoais do médico devem ficar de fora, pois podem ir de encontro aos melhores interesses do paciente.

Porém, o que vemos sendo apoiado pelas leis e associações médicas é que o profissional de saúde pode escolher a quem atender, não tendo a obrigação de atendimento àqueles que não puderem pagar por seus serviços. Ainda assim, grande parte dos médicos providos de caráter se sentem na obrigação de atender a essas pessoas, mesmo não obrigados por lei. A diferença entre a lei e a moral é clara, pois a lei não obriga a fazer o bem, mas exige não causar danos, de modo que a linguagem moral preza mais o princípio da beneficência do que a mera não maleficência.

No artigo "Allocation of resources at the bedside" ${ }^{4}$ Pellegrino lembra o fato de que os médicos 
recebem seu treinamento e conhecimento, e desenvolvem suas habilidades, como resultado de um acordo com a sociedade. A eles é permitido dissecar cadáveres, pesquisar com seres humanos, realizar exames físicos, autópsias, auxiliar no cuidado de pacientes, definir procedimentos práticos e, mesmo, buscar conhecimento acerca da vida emocional e privada dos pacientes, recursos só permitidos por conta da profissão que vão exercer.

A sociedade permite que pessoas inexperientes ganhem habilidade e prática desse modo, porque precisa de médicos e a única forma de prover as capacidades dos mesmos, de modo seguro, é pela experiência. Médicos, por sua vez, recebem benefícios pelo uso das habilidades adquiridas. Na verdade, há um acordo implícito quando os discentes iniciam seus estudos de medicina. Como resultado, possuem o conhecimento médico como guardiões ou gestores desse conhecimento para os doentes.

Os médicos não são mestres absolutos de seu conhecimento. Como retorno pelo que foram permitidos aprender, devem cuidar daqueles que precisam de suas habilidades ${ }^{4}$. Pellegrino chama esse dever de o médico cuidar dos doentes de dever fiduciário, ou seja, um dever que advém da confiança depositada pela sociedade e de todo o conhecimento e experiência fornecidos.

Quanto às questões econômicas que podem estar envolvidas nas práticas clínicas, Pellegrino salienta que diferenças no atendimento são permissíveis quando se referem a luxuosos quartos de hospital, comida sofisticada e outras coisas que não são necessariamente parte do cuidado médico, e dizem respeito à hotelaria hospitalar. Estas podem ser fornecidas àqueles que puderem pagar, ou seja, dois níveis de tratamento são permissíveis, mas apenas no que se refere às comodidades e não em relação à qualidade médica do cuidado.

\section{A experiência da doença}

Pellegrino mostra como alguns conceitos da fenomenologia podem ajudar a melhor compreender a relação médico-paciente, haja vista acreditar que a ética baseada no encontro clínico relata as experiências concretas de médicos e pacientes, mais que a aplicação de teorias éticas preexistentes. Assim, uma abordagem fenomenológica, em sentido amplo, começa com a reflexão acerca da experiência compartilhada pelo médico e paciente.

Essa abordagem heurística se daria a partir dos conceitos de epoché e redução, bem como os conceitos de mundo da vida e intersubjetividade. Pelos primeiros teríamos a etapa de abstração do mundo, na qual se procura interpretar uma experiência buscando suspender as interpretações que naturalmente se daria ao caso, visando conseguir uma espécie de essência que não provenha do mundo. É uma forma de mudança de atenção da fatuidade e particularidade para as qualidades essenciais e universais.

Em paralelo, quando se fala de mundo da vida e intersubjetividade se está dando enfoque às nossas atitudes naturais diante de uma situação, o modo comum de as pessoas agirem, essa realidade comum que compartilhamos, pois o mundo da vida não é privado, já que outros existem, são dotados de similar consciência e compartilham mais ou menos a mesma realidade ${ }^{5}$.

Neste contexto, o mundo da vida dos médicos e dos pacientes pode ser entendido dentro desse conceito de intersubjetividade, já que compartilham a experiência da doença, da cura, de ser curado e de dar esperanças de cura, e juntamente com o conceito de epoché permitiriam uma total construção da realidade social desse encontro médico-paciente.

Assim, a ética fenomenológica deve ser baseada na experiência, não sendo, no entanto, uma ética baseada apenas na prática. $O$ mundo da vida do médico e do paciente é a realidade do encontro clínico, de modo que somente eles sabem o significado desse encontro e como a ética é incorporada nesse contexto. Ou seja, o significado não é um dado bruto, mas nossa percepção humana desse dado, seu significado no mundo da vida.

O que Pellegrino procura mostrar por meio desses conceitos fenomenológicos é que o mundo da vida, de médicos e pacientes, se interpenetra. Que no momento do encontro clínico a relação é condicionada pela intersubjetividade: de uma pessoa que sofre de uma doença e procura cuidado, e de outro ser humano que possui conhecimento e capacidade necessária para cuidar da pessoa doente. Nessa relação, a apreensão intersubjetiva do que é cuidado e o que é dano para este paciente em particular é crucial: $O$ telos da medicina é a cura, e a medicina enquanto medicina é um conjunto de atividades humanas que possuem um fim e um propósitotanto para médicos quanto para pacientes -, o ato da cura, de 'tornar completo outra vez'. No encontro clínico, o telos é o correto e adequado modo de tratar este paciente 5 .

Assim, pode-se perceber que não há um modo correto de agir na relação médico-paciente em geral, 
mas existe o modo correto de agir naquela relação particular, e isso será compreendido pelo médico e pelo paciente nessa relação intersubjetiva. Para que esse telos seja alcançado, mais uma vez destaca-se a importância da confiança que o paciente tem no médico, visto que este terá acessibilidade ao mundo da vida do paciente e, por este acesso privilegiado, deverá se comprometer com a honestidade intelectual, confiança, coragem e supressão de interesse próprio, para poder agir de forma adequada no processo de cura.

\section{O bem do paciente}

O fim da medicina, como defendemos neste artigo, é buscar o bem do paciente, visto que o seu telos é a cura, ou quando essa não for viável, todo o cuidado paliativo possível, entendido este como o alívio do sofrimento, não só de natureza física, mas também psicossocial e espiritual, conforme definição da Organização Mundial da Saúde (OMS), revista em $2002^{6}$.

Cabe então esclarecer o que seria esse bem. O bem do paciente, segundo Pellegrino, não deve ser visto apenas em termos clínicos, mesmo porque os tratamentos e possibilidades hoje disponibilizados pela medicina nem sempre são de interesse do paciente, pois podem ir de encontro a suas crenças e valores do que seja uma vida boa. Tendo efetiva consciência da complexidade de fatores envolvidos quando se fala de bem do paciente, Pellegrino defende que o bem do paciente é definido de forma a contemplar ao menos esses quatro componentes, hierarquicamente dispostos:

O menor deles é o bem médico, isto é, o bom funcionamento do organismo humano enquanto organismo. Isso inclui tanto o funcionamento físico quanto o psicossocial. É neste âmbito que o médico tem sua maior habilidade. $O$ nível seguinte de bem é a avaliação que o próprio paciente faz de seu bem, a definição das preferências, objetivos e tipo de vida que o paciente deseja ter. Nesse âmbito, o paciente ou seu procurador é o ponto de referência. O próximo nivel é o bem do paciente como um ser humano, uma avaliação em termos de compreensão de leis naturais e do que é próprio à vida de seres humanos enquanto humanos - este nivel do bem do paciente não é definido pelo médico ou pelo paciente. É construído com base em o que é ser um ser humano. Esse ponto de referência é a lei natural. Finalmente, o mais alto bem é o bem espiritual, aquele que deriva do fato de que os humanos são criados e de- signados por um Deus pessoal para uma vida além deste mundo e união com Ele (...). Isto não é definido pelo paciente ou pelo médico. Este é o nível completamente negado ou ignorado na bioética secular, apesar do fato de que todos os pacientes, médicos ou procuradores terão compromisso com alguma forma de fé, ou mesmo de rejeição de alguma fé 7 .

O fim da medicina é devidamente alcançado quando a prática clínica visa os melhores interesses do paciente. Porém, cabe ressaltar que por 'melhores interesses' não entendemos o mero interesse subjetivo, até mesmo porque nem sempre o que o paciente deseja é condizente com seu bem, pois a experiência da doença, como vimos, pode alterar a sua capacidade de tomar decisões que realmente sejam de seus melhores interesses e que certamente tomaria se estivesse em condições normais. Defendemos, portanto, que muitas de nossas decisões são baseadas em crenças equivocadas ou na falta de informações ou conhecimento suficiente das condições às quais tal decisão pode nos levar. Desse modo, ocorre que muitas das decisões dos pacientes não devem ser acatadas pelos médicos, por representarem um mal ao mesmo, ao invés de corroborar para os seus melhores interesses

De acordo com os parâmetros supracitados, o paciente deve ser visto como ser humano em uma sociedade, com características individuais, valores e crenças que devem ser levados em conta pelo médico para, com o paciente, perceber quais procedimentos clínicos atendem a suas expectativas. Ainda que valores e crenças estejam presentes em todas as práticas médicas, e por conseguinte também nas escolhas/recusas dos pacientes por tratamentos, o fato de certos valores ou crenças serem defendidos por alguém não os torna verdadeiros e livres de análise moral. Assim, as preferências do paciente são parte constituinte de seu bem, mas não inquestionáveis, podendo, portanto, ser desconsideradas quando configurarem decisões contra o seu próprio bem e contra o telos da medicina de curar e aliviar o sofrimento. Em outras palavras: as decisões do paciente nem sempre refletem o seu bem, como nos casos em que deseja a morte, por considerar-se um fardo aos seus familiares.

\section{Filosofia e Medicina}

Como inicialmente dito, a abordagem teleológica da bioética fornece respostas satisfatórias e coerentes para os dilemas da bioética clínica, pois ao definir o fim da medicina como a busca dos me- 
Ihores interesses do paciente esclarece também o que seja o bem do paciente, e conceitos como o de futilidade, pelos quais se pode clarificar dilemas bioéticos comuns, como os da eutanásia e suicídio medicamente assistido.

Para Pellegrino, falar em morte beneficente, utilizando o argumento da compaixão, alívio da dor, ou mesmo de não causar dano ao paciente que sofre de dor insuportável, é um grande equívoco. Em seu entender, não se pode atribuir ao ato de matar um paciente o status de ação beneficente, mesmo que com base em argumentos de autonomia, alívio do sofrimento etc. Segundo o autor, o que é frequentemente diagnosticado como dor intratável é, na verdade, dor tratada de forma inadequada, que poderia ser amenizada sem tornar o paciente inconsciente. Ou seja, com a utilização otimizada e criteriosa dos meios disponíveis praticamente não existe paciente cuja dor não possa ser aliviada.

$E$, claro, é preciso entender que dor e sofrimento se manifestam muitas vezes como coisas distintas. Cabe ao profissional que fornece o cuidado paliativo não apenas o alívio eficaz da dor física, mas também o cuidado dos aspectos psicológicos. Por esta razão, as equipes de cuidado paliativo compreensivo costumam ser compostas por profissionais de diferentes áreas, como médicos e psicólogos, além dos membros da família e mentores espirituais, pois muitas vezes o desconforto do paciente com a doença terminal vai bem além do desconforto físico.

Segundo Pellegrino, utilizar o argumento do sofrimento insuportável para apoiar a legalização da eutanásia ou suicídio assistido é, além de equívoco quanto aos aspectos clínicos, uma falácia de composição pois, quando da ocorrência dos raros casos onde a dor do paciente não possa ser tratada, não se segue que se deva aprovar moral ou legalmente os procedimentos de eutanásia e/ou suicídio medicamente assistido. Além de ser um erro lógico e prático, esse raciocínio desresponsabiliza, de certa forma, os profissionais de saúde de fornecer os cuidados paliativos adequados para o alívio da dor e sofrimento dos pacientes, além de poder implicar no emprego dessas práticas como meio de controle social ${ }^{8}$. Argumentar a favor da eutanásia ou do suicídio medicamente assistido pode implicar a exposição de pacientes que, em sua situação de vulnerabilidade, podem ver estas práticas como a única saída para o alívio de seus sofrimentos.

É um equívoco fazer generalizações a partir de poucos casos particulares incentivando as ações de apoio à legalização da eutanásia e suicídio medicamente assistido, pois mesmo nos casos mais extre- mos de dor intensa em pacientes em estado terminal o uso de altas doses de opioides pode ser considerado, ainda que se saiba da possibilidade destes medicamentos abreviarem a vida do paciente, pois nesse caso aplica-se o princípio do duplo-efeito (pois o objetivo é aliviar a dor e não antecipar a morte do paciente). Além disso, vale ressaltar, sofrimento não é sinônimo de dor. Pellegrino define sofrimento como a resposta consciente de uma pessoa ao significado e implicações da dor e à situação única da vida em que a dor ou outras formas de alteração na vida ocorrem ${ }^{8}$.

Assim, antes de qualquer coisa, as causas do sofrimento devem ser identificadas. Quando a dor acompanha o sofrimento, deve ser aliviada pelos mais efetivos meios disponíveis. Porém, para aliviar o sofrimento, requer-se muito mais que isso. O uso hábil de antidepressivos e medicamentos contra ansiedade são indicados, bem como o apoio emocional e a presença junto à pessoa que sofre. Desse modo, Pellegrino descreve o cuidado paliativo compreensivo como uma abordagem integrada, que visa não apenas o alívio da dor, mas também do sofrimento do paciente.

Com essa abordagem, examina vários aspectos da doença, já que - como busca ressaltar em seus escritos e palestras - o fenômeno da doença modifica a pessoa, colocando-a em situação de ansiedade, fragilidade e vulnerabilidade. Por isso, é de vital importância examinar o próprio fenômeno da doença para entender os motivos que levam um paciente a desejar a morte. Entendendo-os, podemos oferecer melhor cuidado paliativo, que tornaria as discussões acerca de eutanásia e suicídio medicamente assistido desnecessárias:

Pacientes afetados por doença fatal que ainda não estão em estágio terminal sofrem com antecipação da dor. Pacientes terminais ou que estão morrendo sofrem com medo da morte e medo do processo de morrer. Eles também sofrem de um sentimento de culpa por estarem doentes, por se sentirem como um fardo para outros, em termos físicos, financeiros e emocionais, ou por fazer seus familiares sofrerem por eles (...) Pacientes também sofrem com a pena, medo, ou pela aversão que eles sentem por parte das pessoas saudáveis que vêm visitá-los. Médicos, enfermeiras, visitantes, familiares e amigos podem, sem querer, induzir a sentimentos de invalidez, rejeição e alienação pelo modo que agem na presença dos doentes que estão morrendo ${ }^{8}$.

Todos esses fatos ajudam a entender a necessidade de cuidado paliativo compreensivo, que veja 
o paciente em sua condição e o ajude a superar seu sofrimento físico e emocional, dada a complexidade da experiencia de estar doente, sobretudo quando se trata de doença em estágio terminal. Nesta fase o paciente tem que lidar com todos esses sentimentos que se somam ao medo da morte e da dor que a doença pode causar de forma ainda mais intensa.

Pellegrino interpreta esses rogos por eutanásia ou suicídio medicamente assistido como pedidos de ajuda que os pacientes fazem aos seus cuidadores para lidarem com o seu sofrimento e dor. A vontade de morrer pode ser um desesperado movimento para chamar atenção acerca de sua experiência da doença e sofrimento. Pode também ser expressão de desapontamento com a falta de compaixão da família ou do cuidador, ou seja, atitude que pode ser fruto de falha de compreensão dos que o rodeiam acerca de suas necessidades - ou resposta à fadiga física e emocional que o paciente percebe em sua família, médico ou enfermeiro.

Como afirma Pellegrino, é uma injustiça oferecer a esses pacientes suicídio assistido ou eutanásia como opções, enquanto que tantas outras possibilidades podem ser fornecidas, no que se refere a tratamentos sofisticados ${ }^{8}$. O fulcro da questão é que parece mais fácil oferecer suicídio assistido que um cuidado paliativo de qualidade, pois isso exige muito comprometimento, tanto por parte do profissional de saúde como de toda a equipe médica e familiares.

Pacientes tratados com cuidado paliativo compreensivo e intensivo raramente vão pedir antecipação de suas mortes; se pedem, acabam mudando de ideia, pois os motivos que os levam a esse tipo de decisão são identificados e todo o suporte necessário - físico, psicológico e espiritual - é fornecido. Com isso, Pellegrino não está atribuindo má intenção aos cuidadores, mas reconhecendo as demandas emocionais e a realidade de fadiga e frustração envolvida no cuidado de pacientes terminais. Frente a isso, mesmo as pessoas que mais defendem a autonomia do paciente para demandar procedimentos de abreviação da vida devem reconhecer esta realidade envolta na experiência da doença, e o modo que esta pode alterar nossa própria visão acerca do cuidado se a eutanásia ou o suicídio medicamente assistido se tornarem opção legal ou moral.

Cabe ressaltar que quando se fala de tratamento paliativo compreensivo e intensivo não se está falando em melhorar o tratamento em termos de tecnologia; aliás, o exagero nos tratamentos aplicados pode trazer mais danos que benefícios ao paciente. Fazer tudo o que for possível não necessariamente melhora o cuidado de pacientes terminais, visto que certos tratamentos são desnecessários e fúteis. Além disso, um fato apontado como motivo para o apoio ao suicídio medicamente assistido, mesmo por pessoas que normalmente se oporiam a esta prática, é justamente o medo de serem mantidas vivas por tubos, fios e máquinas quando a vida está chegando ao seu fim por motivos de idade ou doença. Ou seja, a preocupação de muitas pessoas é quanto aos tratamentos inapropriados e invasivos, que não se configuram real benefício aos pacientes, mas, ao invés disso, motivo de temor e sentimento de incapacidade.

Esse problema pode ser resolvido pelo respeito à autonomia do paciente no que concerne ao direito da recusa de tratamento, embora esse direito tenha sido confundido por alguns pacientes como o direito de demandar tratamentos, mesmo que considerados fúteis, de acordo com os médicos, ou eticamente inadequados. O fato de que médicos não têm um controle adequado das doenças terminais não garante a aprovação de ações como eutanásia ou suicídio medicamente assistido de seus pacientes. O que se espera é que maior atenção seja dada aos pacientes e a seus interesses, para que não haja tratamento excessivo ou insuficiente, visto serem essas circunstâncias que fazem os pacientes desejar por fim às suas vidas, por medo do sofrimento por excesso ou falta de tratamento adequado.

O paciente escolhe a morte quando se vê perdendo o controle da situação, quando se sente desvalorizado, dependente e incapaz. Quando sente dor e sofre pelos mais diversos motivos, que podem ser não apenas físicos, mas também psicológicos, espirituais etc. Como afirmado, Pellegrino acredita que se a dor e a depressão fossem adequadamente tratadas a maior parte dos pacientes abandonaria o desejo de morrer. Outro argumento tão fortemente utilizado como o da autonomia é o da compaixão. A compaixão é um sentimento de empatia que pode levar a ações beneficentes, mas também pode causar danos, pois, como salienta o autor, ter compaixão não significa fazer tudo o que uma pessoa quer:

A verdadeira compaixão exige a vivência do sentimento do outro, entrar na experiência única da pessoa que sofre e compartilhar daquela experiência como um todo. Isso significa doar-se, não sentir pena do sofredor. Estar presente mesmo quando nenhuma fácil solução está disponível pode não ser fácil, mas é essencial para que o paciente tenha uma boa morte, e não para aliviar e satisfazer o observador ${ }^{8}$.

Assim, para Pellegrino, considerar ou sugerir a antecipação da morte de alguém é bem mais um ato de abandono do que a atitude de alguém que 
queira estar junto e dar apoio, já que a compaixão, segundo seu significado etimológico, significaria sofrer com o outro e não eliminar a pessoa que sofre, sentir pena ou desgosto da pessoa e de sua situação. O paciente terminal quer se sentir aceito, não rejeitado - esse tipo de atitude é o que abre espaço para que deseje morrer.

Por fim, considerando os mais diversos aspectos envolvidos no término da vida, Pellegrino conclui que as práticas de eutanásia e suicídio medicamente assistido são atos de maleficência, e não beneficência, como sugerem alguns defensores dessas práticas, pois ao invés de agir de acordo com os melhores interesses do paciente, aliviando seu sofrimento e ajudando-o a viver bem seus últimos momentos, se oferece a morte, o que para o autor jamais pode ser considerada como um interesse do paciente, e os que assim o desejam é porque não estão em pleno uso de suas capacidades mentais, ou sofrem de depressão, ansiedade, angústia e até mesmo dor física, fatores que podem ser revertidos por meio de cuidado paliativo compreensivo e intensivo.

\section{Considerações finais}

Com este artigo buscou-se mostrar como na filosofia da medicina de Edmund Pellegrino a beneficência se justifica como princípio que serve de guia às práticas biomédicas, fundamentada pela ideia de fim da medicina, ou seja, servir ao bem do paciente, o que é definido por meio de quatro elementos: o bem último do paciente, o bem enquanto espécie, o bem como visto pelo próprio paciente e o bem bio- médico. Tendo em vista a consideração deste fim, foram discutidas questões referentes aos pacientes com doenças crônicas ou terminais, especialmente a perspectiva daquele autor sobre a importância do cuidado paliativo intensivo e compreensivo. Acredita-se que o assunto tenha sido elucidado mediante análise do que seja o bem do paciente e em que níveis este cuidado deve ser considerado.

Por fim, as considerações sobre cuidado paliativo que se seguem a essa abordagem podem ser tomadas como tentativa de resposta aos dilemas e discussões sobre eutanásia, suicídio medicamente assistido, aborto etc., bem como à proteção daquele que é (ou ao menos deveria ser) o foco da prática médica: o paciente. Assim, a posição endossada neste artigo afirma a primazia do paciente na construção do sentido da medicina. São as necessidades do paciente que dão sentido e justificam a relação médicopaciente, e não as instituições de saúde, interesses de governo, planos de saúde ou, mesmo, indústrias farmacêuticas e profissionais de saúde envolvidos.

Vimos ainda que o bem do paciente nem sempre é representado por suas escolhas, haja vista que muitas dessas decisões representam um mal ao paciente, ao invés de corroborar para os seus meIhores interesses, o que pode ocorrer por falta de informações ou por decisões baseadas em crenças equivocadas. Portanto, práticas moralmente desejáveis em medicina devem ter como foco o bem do paciente, conforme os quatro elementos apresentados, que pode ser alcançado se não pela cura, mediante cuidados paliativos que previnem ou aliviam o sofrimento de pacientes com doenças crônicas ou em fase terminal.

\section{Referências}

1. Pellegrino ED, Thomasma DC. For the patient's good: the restoration of beneficence in health care. Nova York: Oxford University Press; 1988.

2. Pellegrino ED. Bioethics at the century's turn: can normative ethics be retrieved? J Med Philos. 2000;25(6):655-75.

3. Pellegrino ED. Renewing medicine's basic concepts [foreword]. In: Caplan A, McCartney J, Sisti D, editors. Health, disease and illness: concepts in medicine. Washington: Georgetown University Press; 2004. [tradução da autora]

4. Pellegrino ED. Allocation of resources at the bedside: the intersections of economics, law and ethics. Kennedy Inst Ethics J. 1994;4:314. [tradução do autor]

5. Pellegrino ED. Philosophy of medicine and medical ethics: a phenomenological perspective. In: Khushf G, editors. Handbook of bioethics. Dordrecht: Kluwer; 2004. p. 78-188.

6. Academia Nacional de Cuidados Paliativos. Manual de cuidados paliativos. Rio de Janeiro:

Diagraphic, 2009.

7. Pellegrino ED. Decisions at the end of life: the use and abuse of the concept of futility. In: Juan DVC, Elio S, editors. The dignity of the dying person. Vaticano: Libreria Editrice Vaticano; 2000. p.95. [tradução da autora]

8. Pellegrino ED. The false promise of beneficent killing. In: Emanuel LL, editor. Regulating how we die: the ethical, medical and legal issues surrounding physician-assisted suicide. Cambridge: Harvard University Press; 1998. p. 71-91. [tradução da autora]

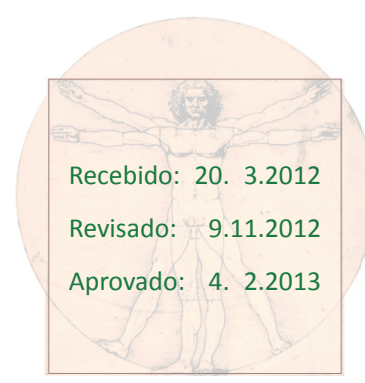

